\title{
Correlation of Histopathological Study of Breast Lesions with Cytology and Mammography as a Measure of Internal Quality and Diagnostic Accuracy
}

\author{
Anusha Mulka, Vaishali Dhananjay Kotasthane*, Rajendra S Dhaka and Dhananjay Shrikant Kotasthane \\ Department of Pathology, Mahatma Gandhi Medical college and Research Institute, Pillaiyarkuppam, Pondicherry, India
}

\begin{abstract}
Background: Breast cancer is the one of the leading causes death in women. Triple test approach has been widely accepted in asymptomatic women for the preoperative diagnosis of the breast lesions. Triple test includes clinical examination, mammography and Fine Needle Aspiration Cytology (FNAC) to differentiate between neoplastic and non-neoplastic lesions, histopathological confirmation being the gold standard for neoplasticlesions and best management plan for the patient.
\end{abstract}

The aim was to study the histopathological spectrum of breast lesions and correlate the cytological and radiological findings with histopathological examination and to determine sensitivity, specificity and diagnostic accuracy of FNACand mammography in the diagnosis of the breast lesions.

Methods: The study comprised of 552 casesofhistopathologically diagnosed breast lesions over the period of twelve years in a rural tertiary health care centre catering rural population.

Results: Of the 552 cases examinedhistopathologically, 375 cases $(67.9 \%)$ were benign lesions, 177 cases (32.1\%) were malignant. Fibroadenoma was the commonest benign lesion, whereas infiltrating ductal carcinoma was the commonest malignant tumour. Incidence of phyllodes tumour was significantly higher compared to other studies. Overall sensitivity, specificity and diagnostic accuracy of FNAC and mammography were $95.9 \%, 98 \%, 96.6 \%$ and $84.7 \%, 78.5 \%, 81.1 \%$ respectively.

Conclusion: Histopathology plays an important role in diagnostic and therapeutic management of neoplastic breast lesionswith preoperative Triple test being an important supportive investigation in rapid diagnosis withfairly good sensitivity,specificity and diagnostic accuracyin neoplastic lesions. Significantly higher incidence of phyllodes tumor needs further investigation for causative mechanism.

Keywords: Triple Test, Histopathology, Cytology, Mammography, Breast lesions, Fibroadenoma, Infiltrating Ductal Carcinoma

\section{Introduction}

Breast lesions are a heterogeneous group of disorders ranging from inflammatory lesions to invasive cancers. [1] Diseases of the breast are showing a rising trend worldwide. ${ }^{[2]}$ Carcinoma of breast is the most common malignant tumour, causing death in women with more than $1,000,000$ cases worldwide annually. ${ }^{[3,4]}$ In India, breast cancer is the second common malignancy after cervical cancer and it is detected in 20 per $1,00,000$ women. ${ }^{[5]}$ About $5-55 \%$ of all females suffer from breast diseases in their lifetime. Benign lesions of the breast are usually seen in the reproductive age, these are thought to be hormone induced and there is drastic fall in incidence, after menopause due to absence of ovarian stimulation. $[6,7]$ Benign Breast Diseases are more common than malignant ones. ${ }^{[8]}$ Benign breast lesions deserve attention because of their high incidence, their impact on women's life and due to cancerous potential of some histological types.
${ }^{[9]}$ Clinically, palpable lump is the commonest presentation followed by nipple discharge and pain along with other symptoms. ${ }^{[10]}$ Many countries performing breast cancer screening programs aimed at detecting early disease in asymptomatic women. ${ }^{[11]}$ "Triple diagnostic technique" which includes Clinical examination, Mammography and FNAC, which determines the diagnosis and assess the need for open biopsy, was suggested by Kreuzer and Boquoi and Hermansen et al. ${ }^{[12,13]}$ Excision biopsy was practiced in the past, but presently, imaging and needle biopsy makes it possible to reduce surgical excision of benign breast lesions to a minimum. ${ }^{[14]}$ Main aim of imaging is early detection of lesions and reducing mortality. The main purpose of fine needle aspiration cytology (FNAC) of breast lump is to confirm cancer pre-operatively and to avoid radical surgery in specific benign conditions. ${ }^{[15]}$

However, the aspiration cytology is not a substitute for conventional surgical histopathology as a definitive 
diagnosis is not always possible by cytology, it also has some limitations but categorization of disease and differential diagnosis can be provided in the majority of cases. ${ }^{[16]}$ With this in mind, an attempt was made to evaluate the breast lesions in context with histopathological correlation of cytological diagnosis to understand the lesion more clearly and also one of the objective tool used for Internal Quality Control. Similar correlation was done with mammography.

The aim of the study was to describe different histopathological lesions of breast in context with age, sex and mode of presentation and to compare these findings with cytological and mammographic findings to calculate sensitivity, specificity and diagnostic accuracy as a quality control measure. The lesions were classified according to recent World Health Organization (WHO) classification tofind out the most common benign and malignant lesions of breast.

\section{Materials and Methods}

This was an analytical study, which was conducted at the Department of Pathology, Mahatma Gandhi Medical College and Research Institute (MGMCRI), Pondicherry which is a rural tertiary care hospital catering rural population of Pondicherry and near-by Cuddalore district of Tamilnadu. The Institutional Human Ethics Committee approved this study. The breast biopsies received through mastectomy or lumpectomy from January 2005 to January 2016 in the Department of Pathology, Mahatma Gandhi Medical College and Research Institute, Pondicherry were included in study. The specimens were analysed with reference to clinical features, gross and light microscopic findings with final histopathological diagnosis. Five hundred and fifty-two breast specimens were received during this period. Histopathology of the tumors was studied along with clinical variables namely age, sex. The tumors were classified according to WHO classification. These findings were analyzed and compared with findings of cytology and mammography wherever available.

\section{Results}

This study included 553 specimens of breast lesions in the Department of Pathology, MGMCRI, Pondicherry. During the study period, the occurrence of breast lesions was maximum in third decade, accounting for 153 (27.7\%) cases. Benign lesions were more common in this age group. There were 89 cases $(16.1 \%)$ in the fifth decade, in which most of the lesions were malignant lesions. In the present study, female predilection was seen. Among the 553 cases studied, 527 cases were females and 26 cases were males. In the present study,most common clinical presentation was breast lump accounting for $90 \%$ followed by nipple discharge and pain.
In histopathological examination of 553 cases, $67.5 \%$ (375) cases accounted for benign lesions. In these benign lesions, $72.3 \%$ were benign neoplasm, majority were Fibroadenomas. Distribution of Benign lesions is shown in Table 1. On Histopathological Examination,32.1\%(177) cases were diagnosed as malignant lesions.Out of these 177 malignant lesions, 154 showed invasive ductal carcinomas and two cases were diagnosed as invasive lobular carcinoma.Distribution of remaining malignant lesions was as shown in Table 2.

Cytological Correlation of Breast Lesions: Out of 553 cases, cytological evaluation was available for 537 cases. Table 3 shows correlation of Cytology and Histology in these 537 cases.[Fig 1 \& 2].Fifteen cytology cases accounted for false negative and four cases for false positive. The sensitivity, specificity, accuracy, positive and negative predictive value of FNAC was found to be $95.9 \%$, $98 \%, 96.6 \%, 99.1 \%$ and $91.3 \%$ respectively.

\section{Radiological correlation of Breast lesions:}

In present study, out of 553cases, 143 patients with palpable breast lump underwent mammography and subsequent pathological examination.[Fig 3 \& 4 4] Mammography showed more malignant lesions than benign because mammography was done after 35 years of age. Comparison ofMammographic diagnosis and Pathological diagnosis was as shown in Table 4. Table 5 shows Radio-Histopathological correlation. I $n$ present study, sensitivity, specificity, accuracy, positive and negative predictive value of mammography was $84.7 \%$, $78.5 \%, 81.1 \%, 73.5 \%$ and $88 \%$ respectively.

\section{Discussion}

Breast lesions are one of the most common lesions encountered in clinical practice. In the present study, the frequency of benign lesions was higher than malignant lesions, as is seen in other studies. ${ }^{[17-22]}$ The present study showed that majority of non-neoplastic cases were in the third decade followed by second decade.Malignant lesions were common after $5^{\text {th }}$ decade. Astudy conducted by other authors also showed similar findings. ${ }^{[19,23,24]}$ Among the benign lesions, fibroadenoma (64.30\%) was the commonest benign breast lesions and fibrocystic disease $(13.9 \%)$ was the second common benign breast lesion with peak occurrence in $3^{\text {rd }}$ decade of life, as seen in other studies. ${ }^{[18,19]}$ In the present study, infiltrating ductal carcinoma was the most common type of invasive carcinoma. Our findings correlated with studies conducted by other authors. ${ }^{[18,25,26,27]}$

In our study, 15 cases reported on cytology turned out to be false negativity.Out of these, 10 cases reported as fibrocystic disease of breast on cytology showed features 
Table 1: Frequency of individual benign breast lesions histopathologically(n=375).

\begin{tabular}{|c|c|c|}
\hline Histopathological diagnosis & No. Of cases & Percentage \\
\hline \multicolumn{3}{|c|}{ 1. Inflammmatory Lesions[n=24 (6.4\%)] } \\
\hline - $\quad$ Breast abscess & 09 & $2.4 \%$ \\
\hline - $\quad$ Chronic mastitis & 07 & $1.9 \%$ \\
\hline - Granulomatous mastitis & 06 & $1.6 \%$ \\
\hline - $\quad$ Duct ectasia & 02 & $0.5 \%$ \\
\hline \multicolumn{3}{|c|}{ 2. Benign proliferative disorders $[n=55(14.7 \%)]$} \\
\hline - $\quad$ Fibrocystic change & 51 & $13.6 \%$ \\
\hline - $\quad$ Sclerosingadenosis & 02 & $0.5 \%$ \\
\hline - $\quad$ Atypical epithelial hyperplasia & 02 & $0.5 \%$ \\
\hline \multicolumn{3}{|l|}{ 3. Benign neoplasm[n=271 $(72.3 \%)]$} \\
\hline - $\quad$ Fibroadenoma & 238 & $63.5 \%$ \\
\hline - $\quad$ Lactating adenoma & 01 & $0.3 \%$ \\
\hline - $\quad$ Phylloidetumour & 23 & $6.1 \%$ \\
\hline - $\quad$ Benign Intra ductal papilloma & 03 & $0.8 \%$ \\
\hline - $\quad$ Lipoma & 02 & $0.5 \%$ \\
\hline \multicolumn{3}{|l|}{ - $\quad$ Tubular adenoma } \\
\hline 4. Miscellaneous[n=25(6.6\%)] & 04 & $1.1 \%$ \\
\hline - $\quad$ Gynecomastia & 25 & $6.7 \%$ \\
\hline - $\quad$ Total & 375 & $100 \%$ \\
\hline
\end{tabular}

Table2: Frequency of individual malignant breast lesions histopathologically

\begin{tabular}{|l|l|l|}
\hline Histopathological diagnosis & No. Of cases & Percentage \\
\hline Invasive duct carcinoma & 154 & $87 \%$ \\
\hline Invasive lobular carcinoma & 02 & $1.12 \%$ \\
\hline Ductal carcinoma insitu & 12 & $6.8 \%$ \\
\hline Medullary carcinoma & 02 & $1.12 \%$ \\
\hline Papillary carcinoma breast & 01 & $0.56 \%$ \\
\hline Mucinous carcinoma & 02 & $1.12 \%$ \\
\hline Malignant phylloides & 03 & $1.69 \%$ \\
\hline Metastatic carcinoma & 01 & $0.56 \%$ \\
\hline Total & $\mathbf{1 7 7}$ & $\mathbf{1 0 0 \%}$ \\
\hline
\end{tabular}

Table3:Cytological and histopathological correlation in general of all breast lesions

\begin{tabular}{|l|c|c|c|c|}
\hline \multirow{2}{*}{$\begin{array}{l}\text { HISTOPATHOLOGICAL } \\
\text { DIAGNOASIS( } \mathbf{n = 5 3 7} \text { cases) }\end{array}$} & Benign & Carcinoma & Suspicious of malignancy & Unsatisfactory \\
\cline { 2 - 5 } Benign lesions (363) & $354[\mathrm{TN}]$ & $3[\mathrm{FP}]$ & $1[\mathrm{FP}]$ & 5 \\
\hline Malignant (174) & $15[\mathrm{FN}]$ & $145[\mathrm{TP}]$ & $14[\mathrm{TP}]$ & 0 \\
\hline Total(537) & $\mathbf{3 6 9}$ & $\mathbf{1 4 8}$ & $\mathbf{1 5}$ & $\mathbf{5}$ \\
\hline
\end{tabular}

$T N=$ true negative, $T P=$ true positive, $F N=$ false negative, $F P=$ false positive

Table 4: Radiological correlation of breast lesions

\begin{tabular}{|l|l|c|}
\hline BIRADS $\mathbf{n = 1 4 3 ( \% )}$ & Histopathological diagnosis & Total No. Of cases(143) \\
\hline BIRADS -I 0 & - & - \\
\hline & acute suppurative lesion & 01 \\
BIRADS-II-27 (19\%) & ductal carcimona-in-situ & 01 \\
& Fibroadenoma & 14 \\
& fibrocystic disease & 10 \\
\hline
\end{tabular}




\begin{tabular}{|l|l|c|}
\hline BIRADS $\mathrm{n=143( \% )}$ & Histopathological diagnosis & Total No. Of cases(143) \\
\hline \multirow{2}{*}{ BIRADS-III-32(22\%) } & Benign & 25 \\
& Malignant & 07 \\
\hline \multirow{2}{*}{ BIRADS-IV- 25(17\%) } & Benign & 15 \\
\hline \multirow{2}{*}{ BIRADS-V- 36 $(25 \%)$} & Malignant & 11 \\
\hline BIRADS-VI-23 (16\%) & Benign & 03 \\
\hline
\end{tabular}

Table 5: Radio -histopathological correlation

\begin{tabular}{|l|c|c|}
\hline \multirow{2}{*}{ Mammographic findings $(\mathbf{n}=143)$} & \multicolumn{2}{|c|}{ Histopathological diagnosis } \\
\cline { 2 - 3 } & Benign & Malignant \\
\hline Benign [BIRADS I,II,III] $(59)$ & 50 & 09 \\
\hline Malignant[BIRADS IV, $\mathrm{V}, \mathrm{VI}](84)$ & 18 & 66 \\
\hline
\end{tabular}

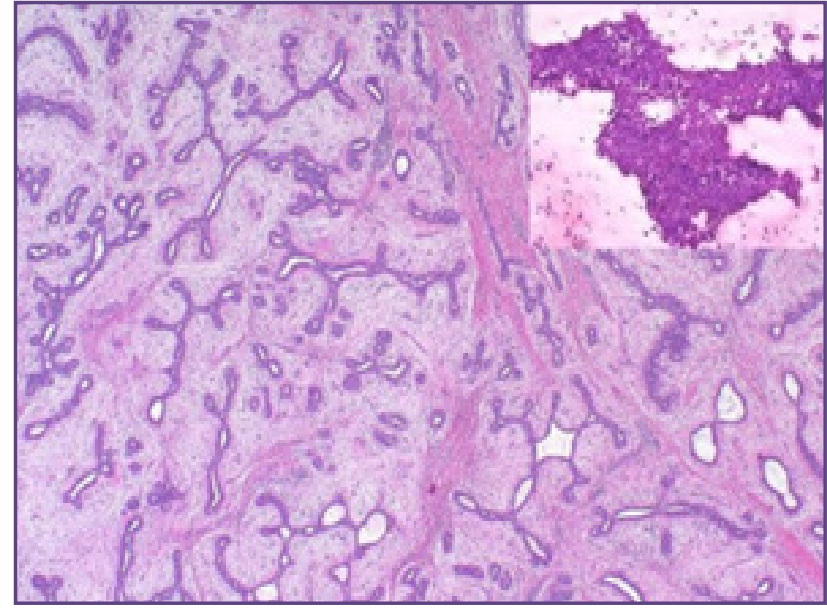

Fig. 1: Fibroadenoma showing predominantly intracanalicular pattern.(H\&E 10x) Inset: cytology showing monolayered sheets of monomorphic cells with bare nuclei in the background (H\&E 10x)

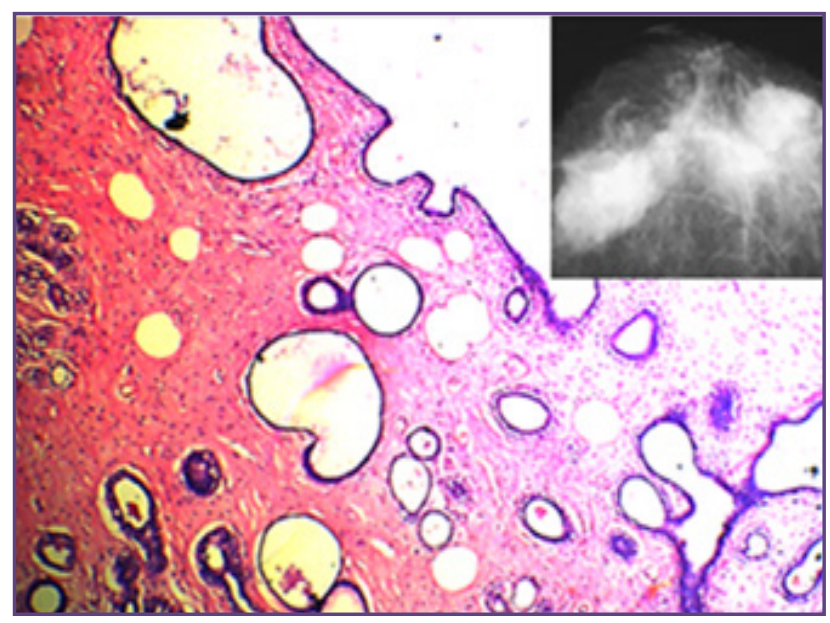

Fig. 3 :Fibrocystic change showing epitheliosis, cystically dilated glands. (H\&E 10x). Inset: Mammography showing low density round calcification in multiple lobules.

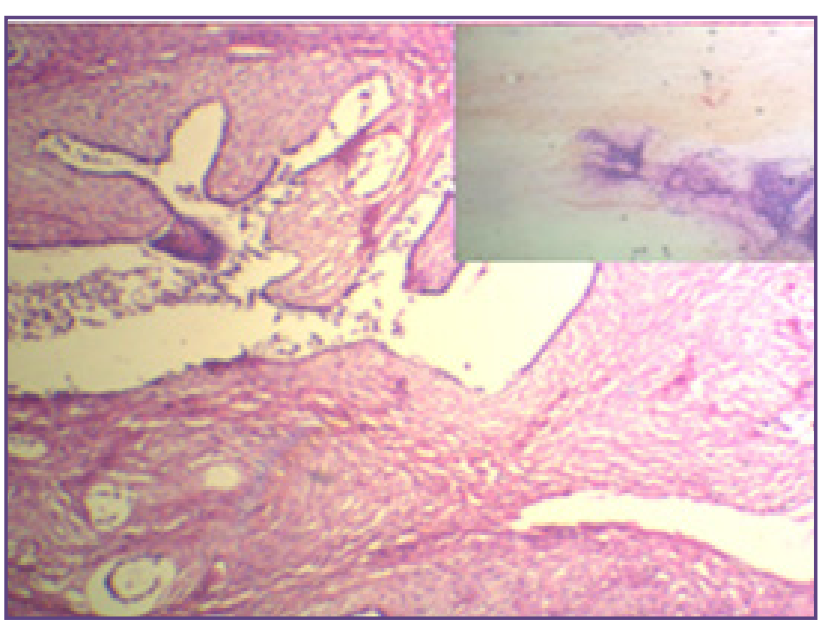

Fig. 2: Benign Phyllodestumor showing leaf-like proliferation of stromal cells(H\&E 10x). Inset: Cytology showing spindle shaped stromal cells.(H\&E 4x).

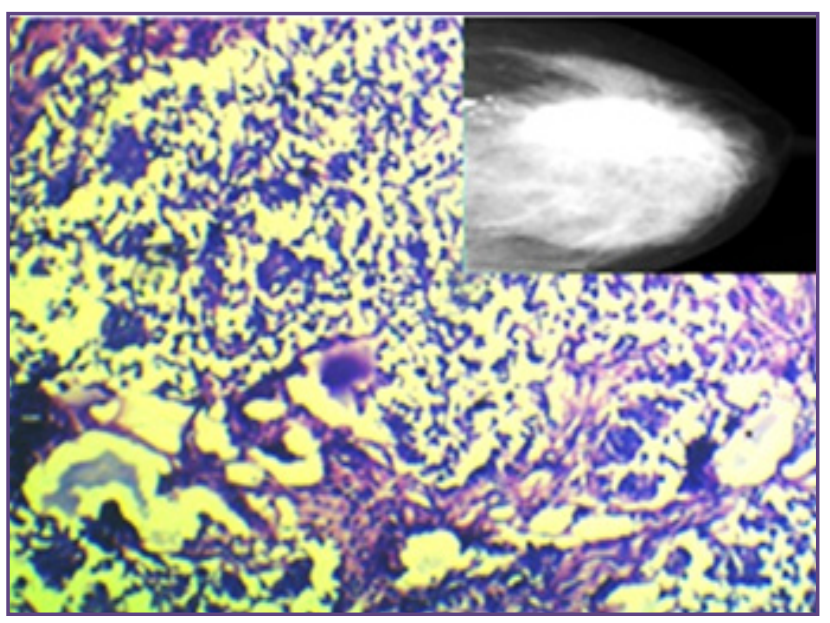

Fig. 4: Infiltrating ductal carcinoma NOS type.(H \& E 10x) Inset:mammography showing irregular radio-opaque lesion with speculated margins. 
of low grade DCIS on histology. Five cases reported as benign proliferative breast disease with atypia on cytology showed features of Infiltrating Ductal Carcinoma in 3 cases and lobular carcinoma in 2 cases on histology. This was due to inappropriate sampling and non targeted FNAC. This is one the common pitfalls and diagnostic dilemma of cytology, due to non-availability of architecturalfeatures and low grade cytological atypia on cytology smears.USG guided targeted FNAC can be helpful in diagnosis of missed out lesion. Careful evaluation of cytological features and adhering to criteria of adequacy of smear could be helpful to overcome these pitfalls.Also, reporting on smears with low cellularity should be avoided by repeating FNAC so that adequacy criteria are satisfied.In our study, four cases accounted for false positive cases. This can be avoided by correlating with mammographic and clinical features and advising biopsy in suspicious cases. The overall accuracy of cytology in diagnosis of breast lesions has been reported to be $95 \%$ to $100 \%$ in various studies in literature. The sensitivity, specificity and diagnostic accuracy of FNAC in other studies was comparable with our study. ${ }^{[28,29]}$ FNAC is the mainstay in the diagnosis of breast lesions, but it cannot always be relied upon in isolation.FNAC should be used with the idea of 'complimenting', not competing with routine Histopathological examination.

In the present study, pitfalls were also found in mammography. Fifteen cases reported as BIRADS IV on mammography, turned out to be benign on histopathology and three cases reported as BIRADS V, turned out to be malignant on histopathology.In the present study, sensitivity and specificity of mammography was $84.7 \%$ and $78.5 \%$ respectively. These results were close to Taori et al's findings, where as studies conducted by Warren and Baker found higher diagnostic accuracy of $85 \%$ and $89 \%$ respectively in mammography. ${ }^{[30,31,32]}$ This indicates that histopathological evaluation remains the golden Standard.

The current study provides Hospital based epidemiological data on Correlation of Histopathological diagnosis with Cytological and Radiological diagnosis for a period of 12 years.

\section{Conclusion}

The present study highlights importance of histopathological correlation to find the true nature of the lesion. Histopathological study acts as an internal quality measure for Cytological and Mammographic diagnosis and is the gold standard for diagnosis of neoplastic lesions.

\section{References}

1. Guray M, Sahin A. Benign Breast Diseases: Classification, Diagnosis and Management. Oncologist. 2006; 11(5): 435-49.
2. Ibrahim E M, Zeeneldin A A, Sadiq BB, Ezzat AA. Breast Cancer in Saudi Arabia Incidence Developing Country. Medical Oncology. 2008; 25:387 - 393

3. Parkin DM, Bray F, Ferlay J, Pisani P. Estimates the world cancer burden. Globocon 2000.Int J cancer. 2001; 94: 153-56.

4. Rahbar G, Sie A C, Hansen GC, Prince JS, Melany ML, Reynold HE, Jackson VP, Sayre JW and Bassett LW. Benign versus solid breast Masses: US differentiation. Radiology 1999; 213: 889-94.

5. Desai M. Role of obstetrician and gynecologist in management of breast lump. J Obst Gynaecol India.2003; 53:389-91.

6. Santen RJ, Mansel R. Benign breast disorders. N Engl J Med. 2005; 353:275-85.

7. Douglas J, Merchant MD. Benign Breast Diseases. Obst Gynaecol Clinics of North America. 2002; 29(1): 1-2.

8. Haagensen CD. The basis forthe histologic grading of carcinoma of the breast. Amer. Cancer 19 (1933), 235. Diseases of the breast. WB Saunders Co., Philadelphia and London: 1956.

9. Goehring C, Morabia A .Epidemiology of Benign Breast Disease, with Special Attention to Histologic Types. Epidemiol Rev.1997; 19(2):310-22.

10. Dixon J M, Mansel RE.ABC of breast diseases. Symptoms assessment and guidelines for referral. BMJ. 1994; 309(6956):722-26.

11. Sankaranarayanan R, Ramadas K, Thara S, Muwonge R, Prabhakar J, Augustine P et al. Clinical breast examination: preliminary results from a randomized controlled trial in India. J of Natl Cancer Inst.2011; 103:1476-80.

12. Kreuzer G, Boquoi E. Aspiration biopsy cytology, mammography and clinical exploration: a modern set up in diagnosis of tumors of the breast. Acta Cytol. Jul-Aug1976; 20(4):319-23.

13. Hermansen C, Skovgaard Poulsen H, Jensen J, Langfeldt B, Steenoskov V, Frederiksen P, Myhre Jensen O. Palpable breast tumors: "triple diagnosis" and operative strategy: Results of a prospective study. Acta Chir Scand.1984;150(8): 625-28.

14. Ahmed HG, Ali AS, Almobarak AO. Frequency of breast cancer among Sudanese patients with breast palpable lumps. Indian J Cancer 2010; 47:2326.

15. Hand U, Mohan H, Bharadwaj S, Punia RPS. Fine needle aspiration as a diagnostic tool in breast lesions.I J S 2000; 62: 125-27.

16. Hari S, Srivastava A, Thulkar S. Scope of Breast Imaging in Developing Countries.NJR. 2013;vol 3(2):11-30.

17. Amr SS, Rahman A, Sadi M, Ilahi F, Sheikh SS. The Spectrum of Breast Diseases in Saudi Arab Females: A 26 yr Pathological Survey at Dhahran Health Center. Ann Saudi Med. 1995; 15(2):125-32.

18. Malik R, Bharadwaj VK. Breast lesions in young females - a 20 year study for significance of earlyrecognition. Indian $\mathrm{J}$ Pathol Microbiol. 2003; 46:559-66. 
19. Kulkarni S, Vora I M, Ghorpade K G, Shrivastava S. Histopathological spectrum of breast lesions with reference to uncommon cases. Obst Gynecol India. 2009; Vol.59(5):444-52.

20. Rasheed A, Sharma S, Rasool M, Bashir S, Hafiz A, Bashir N. A three year study of breast lesions in women aged 1570 years in a tertiary care hospital. Sch J App Med Sci. 2014;2(IB):166-68.

21. Iyer SP, Gore MA. Epidemiology of Benign Breast Diseases in Females of Child Bearing age group.(internet). http:// www.bhj.org.in/journal/2000_4201_jan00/original_141.htm

22. Mayun AA, Pindija VH, Babayo UD. Pattern of histopathological diagnosis of breast lesion in Gombe, Nigeria. Nigerian J Med. 2008; 17(2):159-62.

23. Bagale P, Dravid NV, Bagale S, Ahire N. Clinico-pathological study of benign breast diseases. Int J Health Sci Res. 2013; $3(2): 47-54$.

24. Ibrahim IM, Iliyasu Y, Mohammed AZ. Histopathological review of breast tumors in kano, Northern Nigeria. SubSaharan Afr J Med. 2015; 2: 47-51.

25. ur-rehman A. Histopathological Analysis of Consecutive 161 cases of Breast Lumps. Pak J Med Health Sci. 2013; 7(3): $624-25$.
26. Mudholkar VG, Mashal SN, Kawade SB. Histopathological Study of Neoplastic Lesions of Breast.Indian Medical Gazette. 2012;145(9):353-64.

27. Bane AL, Beck JC, Bleiweiss I, Buys SS, Catalano E, Daly $\mathrm{MB}$ et al. BRCA2 Mutation- associated Breast Cancers exhibit a distinguishing phenotype based on morphology and molecular profiles fromtissue microarrays. Am J Surg Pathol. 2007;31:121-28.

28. Pant I, Singh PK, Singh SN, Agarwal A, Singh NB. Cytomorphologic study of palpable breast lesions and histopathologic correlation. Journal of Cytology. 2003; 20 (3): 129-32.

29. Vala MT, Goswami A, Suri SK. Comparative study of cytological and histopathological finding in breast lesion. IOSR Journal of Dental and Medical Sciences (IOSRJDMS). 2014;13(7): 5-7.

30. Taori K, Dhakate S, Rathod J, Hatgaonkar A, Disawal A,Wavare P. Evaluation of Breast Masses Using Mammography and Sonography as First Line Investigations. Open Journal of Medical Imaging.2013;3: 40-49.

31. Warren SL. Roentgenologic study of breast. AJR 1930; 4:113.

32. Baker LH. Breast Cancer Detection Demon- stration Project: Five-year summary report. CA. 1982;32:194-225.

*Corresponding author:

Dr. Vaishali Dhananjay Kotasthane, Department of Pathology, Mahatma Gandhi Medical college and research Institute,

Pillaiyarkuppam, Pondicherry- 607402,India

Phone: +918124054684

Email: vaishalikotasthane@gmail.com,

Date of Submission : 22.03.2017

Financial or other Competing Interests: None.

Date of Acceptance : 25.04.2017

Date of Publication : 31.08.2017 